American Journal of Applied Sciences 8 (7): 708-715, 2011

ISSN 1546-9239

(C) 2011 Science Publications

\title{
Characterization of the Genetic Diversity of Peach Cultivars in Taif by RAPD-PCR
}

\author{
${ }^{1,2}$ Mohamed A. Nagaty, ${ }^{1,3}$ Salah El-Din El-Assal and ${ }^{1,4}$ Mahmoud M. Rifaat \\ ${ }^{1}$ Department of Biotechnology, Faculty of Science, Taif University, Taif, KSA \\ ${ }^{2}$ Department of Plant Production, Faculty of Environmental Agricultural Sciences, \\ Suez Canal University, Egypt \\ ${ }^{3}$ Department of Genetics, Faculty of Agriculture, Cairo University, Egypt \\ ${ }^{4}$ Department of Genetics, Faculty of Agriculture, Suez Canal University, Egypt
}

\begin{abstract}
Problem statement: Peach genotypes from the Kingdom of Saudi Arabia were not adequately characterized at the biological and molecular levels. This study was carried out to characterize nine peach cultivars growing in Taif (KSA) at the biological and molecular levels. Approach: For the nine peach cultivars studied, flowering and fruiting indices were determined and eight, 10-base primers were used to amplify DNA from each cultivar by using Randomly Amplified Polymorphic DNA (RAPD) technology. RAPD profiles (i.e., cultivars) and RAPD amplicons (i.e., markers) were biclustered by using appropriate software and the RAPD biclusters were viewed as a heatmap in order to improve the display of RAPD markers. Results: The different RAPD primers produced a total of 114 fragments (amplicons), of which 63 were polymorphic among the studied cultivars. The RAPD fingerprinting results confirmed the data obtained from the morphological analyses and allowed for estimating the genetic relatedness among the studied peach cultivars. Moreover, the data indicated that certain molecular markers might be associated with certain commercial characteristics. Conclusion/Recommendations: Future studies on the association(s) of the selected molecular markers with fruiting characteristics should allow for new gene discovery, molecular breeding, proper biodiversity assessment and better conservation of germplasm resources.
\end{abstract}

Key words: Molecular markers, cultivars growing, genetic diversity, peach cultivars, RAPD fingerprinting, appropriate software, nucleotide variability, Randomly Amplified Polymorphic (RAP), genetic analysis

\section{INTRODUCTION}

Peach (Prunus persica L. Batsch) is one of the important stone fruits and is also considered to be one of the most favorable crops for farmers worldwide. Peach is a self-fertile and naturally self-pollinating fruit species with very low genetic variability (Pedryc et al., 2009). Molecular markers are markers based on the length polymorphism of DNA sequences that have revolutionized plant breeding and are now being applied to a variety of topics such as the selection of genotypes assisted by trait-linked markers, mapping Mendelian and quantitative traits loci, fingerprinting individuals and the genetic analysis of both populations and individuals (Nas et al., 2011). The International Peach Genome Initiative (IPGI) has released the early online access to the draft assembled and annotated peach genome sequence (peach v1.0; April, 2010). This has opened a new era in the genomics of Prunus species and stimulated the interest in the discovery of nucleotide variability within the peach germplasm through whole genome resequencing of the divergent peach accessions. Expressed sequence tags (EST) were used for genome annotation, gene expression, and comparative genomics between Prunus species (Li et al., 2010), and identification of genes involved in fruit development and maturation (Falchi et al. 2010), signaling pathway leading from photoperiod perception to growth cessation and dormancy (Jimenez et al., 2010). Mutation scanning technology has been used to develop crop species with improved traits. Chen and Wilde (2011) used two high-resolution melting (HRM) analysis methods for the discovery of SNPs in exons of peach genes of cultivars from a southeastern US. The SNP variability in peach genome was considerably lower than that observed in maize and grapevine (Verde et al., 2011), which is attributable to the peach domestication processes. 
Randomly Amplified Polymorphic DNA (RAPD) markers could represent an interesting source of polymorphic markers as it harbors considerable length variation between individuals and is extremely abundant in eukaryotic genomes. Among the array of DNA, markers were available by the introduction of the techniques of DNA detection and amplification, only RFLPs (restriction fragment length polymorphisms) and RAPDs (random amplified polymorphic DNAs) have been adopted in the genetic analysis of the peach, mainly with the aim of constructing linkage maps (Bouhadida et al., 2009).

Peach cultivars in USA and Europe were molecularly characterized, while resources of peaches from the Kingdom of Saudi Arabia were not characterized adequately. In the present study, RAPD PCR was used to profile nine peach cultivars growing in Taif, Kingdom of Saudi Arabia. These cultivars were also characterized at the biological level with respect to several flowering and fruiting parameters. A biclustering algorithm was applied to cluster RAPD profiles (genomes) and RAPD markers (amplicons) in order to detect structurally relevant RAPD PCR markers. The ultimate objective of the study was to estimate the genetic relatedness among the nine local peach cultivars and to identify RAPD markers that could be used to follow up important flowering and fruiting traits in peach breeding programs.

\section{MATERIALS AND METHODS}

Studied peach cultivars: Early-to-late maturing local peach grown in Taif governorate were sampled and subjected to molecular and biological studies. According to the Cultivated Plant Code, the cultivars studied were: Prunus persica (L.) Batsch 'Balady Sofiani', Prunus persica (L.) Batsch 'Ordony El-mofti' . Prunus persica (L.) Batsch 'Balady Mofareg', Prunus persica (L.) Batsch 'Balady M. Thamaly', and Prunus persica (L.) Batsch 'Balady Azab'. The cultivars 'Ordony El-mofti', 'Balady Mofareg', 'Balady M. Thamaly', and Balady Azab were each sampled from two different farms (1 and 2). For the purpose of identifying materials conveniently and operationally, the nine specimens are referred to in the text as 'Balady Sofiani', 'Ordony El-mofti 1', 'Ordony Elmofti 2', 'Balady Mofareg 1', 'Balady Mofareg 2', 'Balady M. Thamaly 1', 'Balady M. Thamaly 2', 'Balady Azab 1', and 'Balady Azab 2' cultivars. 'Ordony El-mofti 1' and 'Ordony El-mofti 2' cultivars were grafted on apricot rootstock, while 'Balady' cultivars were seeded. The studied peach trees were about 5 years old. The plants were spaced at $4.5 \times 2.5$ $\mathrm{m}$ and trained as spindle.

Flowering and fruiting parameters: In February of the experimental season, ten uniform fruit limbs from all over the outer circumference of each tree were tagged for flowering and fruiting measurements. The flowering parameters were carried out at two stages (full bloom and fruit set). Several parameters were performed such as number of opened flowers per each labeled fruit limb, fruit set \% (at 6-7 mm fruit diameter) and average numbers of fruit/fruit limb were calculated. Evaluation of fruit quality was carried out during the maturity stage. Fruits of each cultivar were hand-picked from three trees at the ripeness stage. From each tree, ten fruits with the same diameter, skin color and firmness were selected as representative samples, divided into two groups (five fruits for each) and analyzed within $24 \mathrm{~h}$ for quantitative and sensory analyses. Fruit length; fruit width (using caliper instrument); fruit length, width ratio and average fruit weight (g/fruit) were recorded as quantitative or commercial traits. The Total Soluble Solids percentage (TSS \%) and $\mathrm{pH}$ value were measured in fruit flesh juice (AOAC, 1990). The T.S.S \% was measured by table refract meter (Model N-50E; Atago, Tokyo, Japan) and expressed as ${ }^{\circ}$ Brix at $20^{\circ} \mathrm{C}$. The $\mathrm{pH}$ was determined by using a microprocessor $\mathrm{pH}$ meter (Model: pH 211, HANNA instruments). The mean, standard deviation and standard error of each of the studied parameters were determined using Excel, Microsoft Office, 2007.

Qualitative parameters (sensory analyses) of the studied peach cultivars included fuzz (B1: dense, light); cling stone (B2: freestone, semi-cling, cling); smell (B3: odor, no odor); taste (B4: low (acidic), medium (semi-sweet), high (sweet)); and fruit and flesh colors (B5 and B6: yellow, white, orange yellow, white yellow, red yellow and dull red). All tests were done in clean, quiet, air conditioned and odor free room where each panelist used a separate table during judgments. Fruit and flesh colors were determined by using colour index (Ribereau-Gayon et al., 2006). Cultivars and the qualitative parameters were biclustered by using Cluster and Tree View Software (Satnford University, USA).

\section{Molecular characterization:}

DNA preparation: Fresh young healthy peach leaves were ground to powder with liquid nitrogen using a mortar and pestle. Genomic DNA was isolated from leaf samples using the procedure described by DNeasy Plant Mini Kit protocol (QIAGEN, Germany). 
Am. J. Applied Sci., 8 (7): 708-715, 2011

Table 1: Sequence of the eight arbitrary decamer primers assayed in RAPD analysis

\begin{tabular}{ll}
\hline Primer & Sequence $\left(5^{\prime}-3^{\prime}\right)$ \\
\hline OP-A08 & GTG ACG TAG G \\
OP-A13 & CAG CAC CCA C \\
OP-B07 & GGT GAC GCA G \\
OP-B10 & CTG CTG GGA C \\
OP-B18 & CCA CAG CAG T \\
OP-C20 & ACT TCG CCA C \\
OP-O04 & AAG TCC GCT C \\
OP-Z13 & GAC TAA GCC C \\
\hline
\end{tabular}

RAPD analysis: Eight 10-base random primers were used for PCR amplification (Table, 1). RAPD PCR was performed in Gene Amp ${ }^{\circledR}$ PCR System 9700 (Perkin Elmer, England) in a volume of $25 \mu \mathrm{L}$ containing 10 $\mathrm{mM}$ Tris-Cl pH 9.0, $50 \mathrm{mM} \mathrm{KCl}, 1.5 \mathrm{mM} \mathrm{MgCl} 2,0.2$ $\mathrm{mM}$ of each dNTP, $0.2 \mu \mathrm{M}$ of each primer, $100 \mathrm{ng}$ of genomic DNA and $0.1 \mathrm{U}$ of Taq polymerase (Pharmacia) using the following temperature profile: Hard denaturation at $95^{\circ} \mathrm{C}$ for $5 \mathrm{~min}$; PCR of 35 cycles at $94^{\circ} \mathrm{C}$ for $45 \mathrm{sec}, 40^{\circ} \mathrm{C}$ for $45 \mathrm{sec}$ and $72^{\circ} \mathrm{C}$ for $45 \mathrm{sec}$; and long extension at $72^{\circ} \mathrm{C}$ for $8 \mathrm{~min}$. The amplification products were resolved by electrophoresis into a $2 \%$ agarose gel containing $0.5 \mu \mathrm{g} \mathrm{mL}^{-1}$ ethidium bromide in $1 \mathrm{X}$ TBE buffer at 5 volts, cm. 100bp DNA ladder Marker (Fermentas, Thermo Scientific) was used as standard marker to estimate the approximate molecular weight of the amplified products. The PCR products were visualized under UV illumination and photographed using Bio-Rad® Gel Doc-2000 gel documentation system.

Gel images were analyzed for genetic similarity among cultivars by using AlphaEase Software (Alpha Innotech, CA and USA). RAPD bands were scored as discrete variables, using " 1 " to indicate presence and "0" to indicate absence of a band in the profile. Pairwise similarity (or distance) matrices were constructed and cluster analysis was performed using these matrices with the Unweighted Pair Group Method with Arithmetic averages (UPGMA) method. The RAPD markers were biclustered by using Cluster and Tree View Software as described by Rifaat (2011). All computations were performed using the AlphaEase Software (Alpha Innotech, CA, USA), FORTRAN computer program NTSYSpc,ver. 2.1 (Applied Biostatistics Inc., USA) and Cluster and TreeView Software (Satnford University, USA).

\section{RESULTS}

Flowering and fruiting parameters: Balady Mofareg 2 cultivar showed the highest value of average number of flowers, fruit limb $(23.40 \pm 3.17)$ among the rest of studied 9 peach cultivars. The two cultivars Balady Sofiani and Balady Azab 2 had the lowest average number of flowers, fruit limb $(8.20 \pm 0.99$ and $8.30 \pm$ 2.04 respectively). These two cultivars showed the highest values of fruit setting $(28.85 \pm 3.15$ and $30.59 \pm$ 5.62 respectively) among the 9 peach cultivars. All cultivars were late in flowering compared to the Ordony El-mofti 1 and Ordony El-mofti 2 cultivars.

Fruit length; fruit width; fruit length,width ratio; fruit weight (g, fruit); flesh weight and flesh thickness were recorded as quantitative or commercial traits. Peach cultivars Balady Sofiani; (1) Ordony El-mofti; (2) Ordony El-mofti and Balady Azab 2 showed the highest average fruit weight, flesh weight and flesh thickness values comparing to the rest of cultivars. The fruit weight averages among these four cultivars are $60.91 \pm 0.15,52.98 \pm 0.24,51.9 \pm 0.25$ and $59.66 \pm 0.22$ respectively. Averages for flesh weight were $56.1 \pm 0.15$, $50.06 \pm 1.95,50.02 \pm 0.28$ and $54.90 \pm 0.35$. Moreover, for flesh thickness were $2.10 \pm .02,1.98 \pm 0.01,1.87 \pm$ 0.12 and $2.03 \pm 0.04$ respectively. Fruit Length, width ratio for the studied peach cultivars has reflected the circular shape of most of them, except Ordony El-mofti 1 and Ordony El-mofti 2 were elongated (Fig. 1).

The $\mathrm{pH}$ values of the nine cultivars ranged from 3.7 (Balady Azab 1) -4.3 (Balady M. Thamaly 1). Among the tested cultivars, the fruits of Balady M. Thamaly 1 had the highest TSS $\left({ }^{\circ}\right.$ Brix \%) $(12.38 \pm 0.24)$, while those of Balady M. Thamaly 2 had the lowest TSS $\left({ }^{\circ}\right.$ Brix \%) $(8.5 \pm 1.25)$, as shown in Fig. 1 .

Figure 2 shows the biclustering of the qualitative fruit properties in the studied peach cultivars. All peach cultivars studied had dense fuzz, while most cultivars had semi cling stone and orange yellow flesh color. The other qualitative traits varied among the studied cultivars. These differences are very important for the customer preferences and successful marketing.

\section{Molecular characterization:}

RAPD fingerprinting: We have used RAPD markers to estimate intra- and inter polymorphism among the peach cultivars grown in Taif. These markers were used to rapidly discriminate peach cultivars and to reveal possible correlations between these molecular markers and important peach traits. To this end, genomic DNA prepared from the nine peach cultivars was used in PCRs primed with eight RAPD primers (Fig. 3). The different RAPD primers produced a total of 114 fragments (Table 2), of which 63 (55\%) were polymorphic among the studied cultivars. Li et al. (2010), reported that SSR markers were useful in the evaluation of genetic relationships and diversity between and within the Prunus species and observed a high level of marker polymorphism in the plum species $(65 \%)$ and low level of marker polymorphism in the peach (46\%). 
The RAPD primer OP-B10 showed the highest (84.2\%) polymorphism, while the RAPD primer OPO04 showed the lowest (11.1\%) polymorphism among the studied cultivars, Table 2.

The primer OP-A08 amplified the RAPD amplicon (M11) that was specific to Ordony El-mofti 1 and Balady Mofareg 2 cultivars (Fig. 3A). From Balady Thamaly 2 and Balady Azab 1, the RAPD amplicon M46 was missing from the products of primer OP-B07 (Fig. 3C). Certain RAPD amplicons produced by primer OP-B10 were specific to certain cultivars such as M54 and M58 (Balady Sofiani); M57 (Balady Thamaly 1 and Balady Thamaly 2); and M59 (Balady Thamaly 1). The RAPD markers M50 and M51 were missing from ${ }^{2}$ Balady Azab and Balady Sofiani, respectively (Fig. 3D). The RAPD marker M92 was amplified only from Ordony El-mofti 1 and Ordony Elmofti 2 cultivars by using the primer OP-C20 (Fig. 3F). The primer OP-O04 amplified the marker M93 from
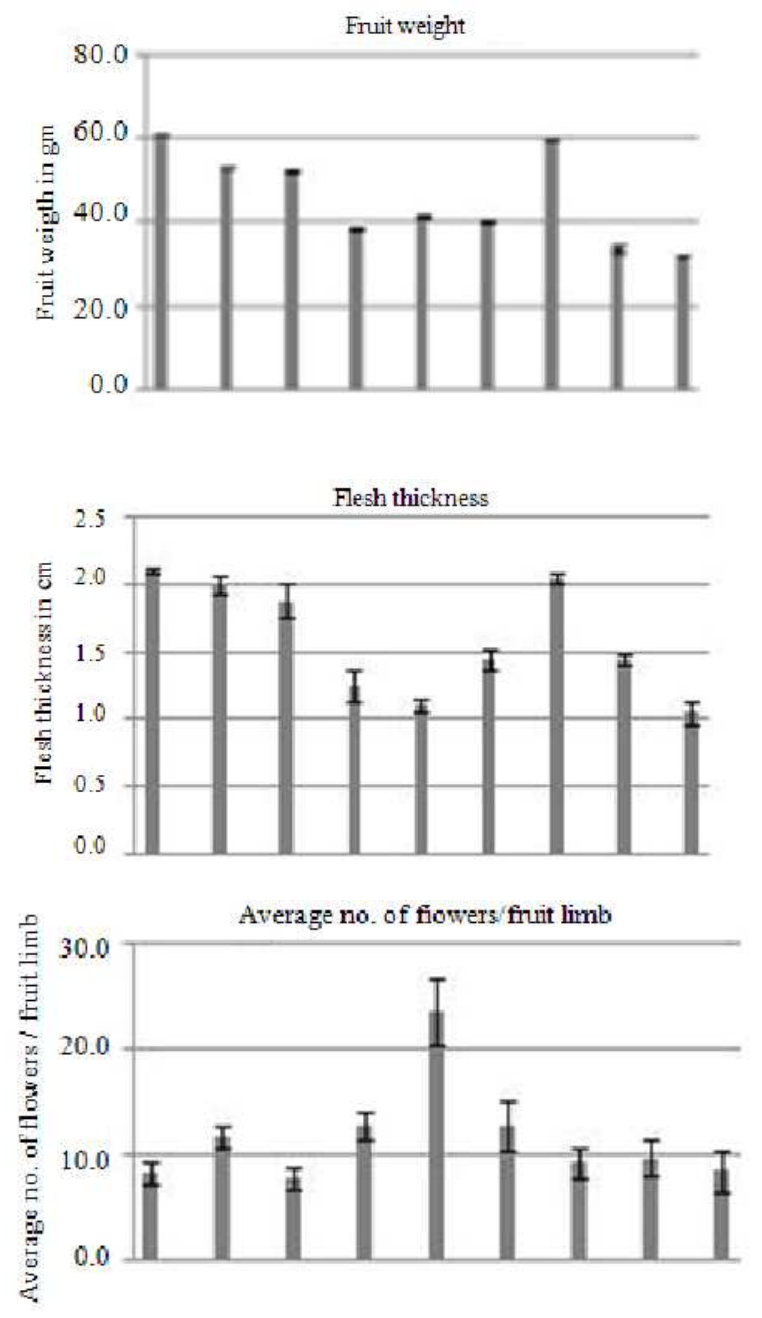

three cultivars only; i.e., Ordony El-mofti 1, Balady Azab 1 and Balady Azab 2 (Fig. 3G). The primer OPZ13 amplified several amplicons that could be used to distinguish several peach cultivars (Fig. 3H).

Based on RAPD profiles, the highest (97.4\%) genetic similarity existed between cultivars Balady Sofiani and Balady M. Thamaly 2 (Table 3). On the other hand, Balady Sofiani and Ordony El-mofti 1 cultivars was the most dissimilar (Table, 3 ).

The nine peach cultivars exhibited two major clusters based on RAPD profiles (Fig. 4). One cluster contained Ordony El-mofti 1 (C2 in Fig. 4) and Ordony El-mofti 2 (C3 in Fi. 4) cultivars which shared the same fruit characters and had the highest genetic similarity $(93.1 \%)$. The other major cluster contained the other seven cultivars. Some speciation pressures could cause around $7 \%$ of genetic differences between these two cultivars. Differences up to $22 \%$ existed between all the seven Balady cultivars that used in this study.
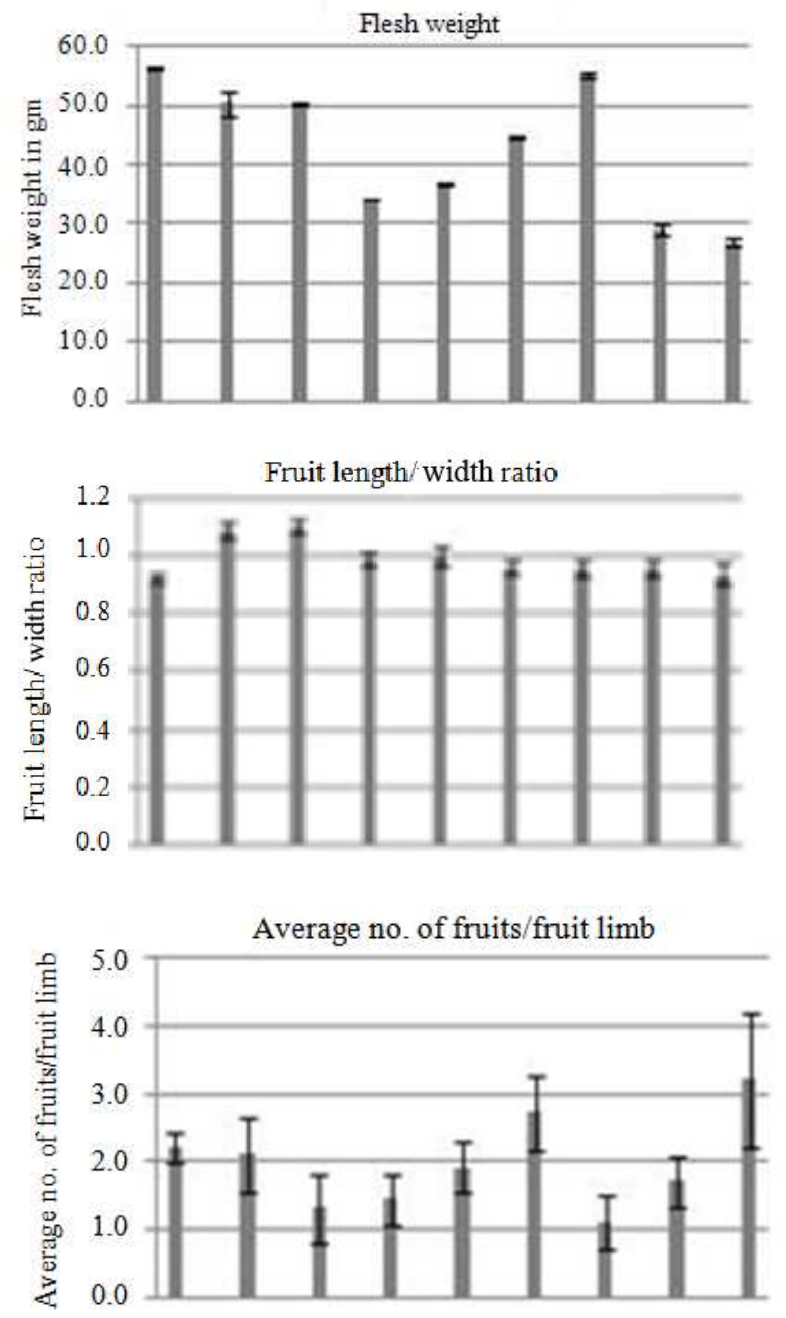

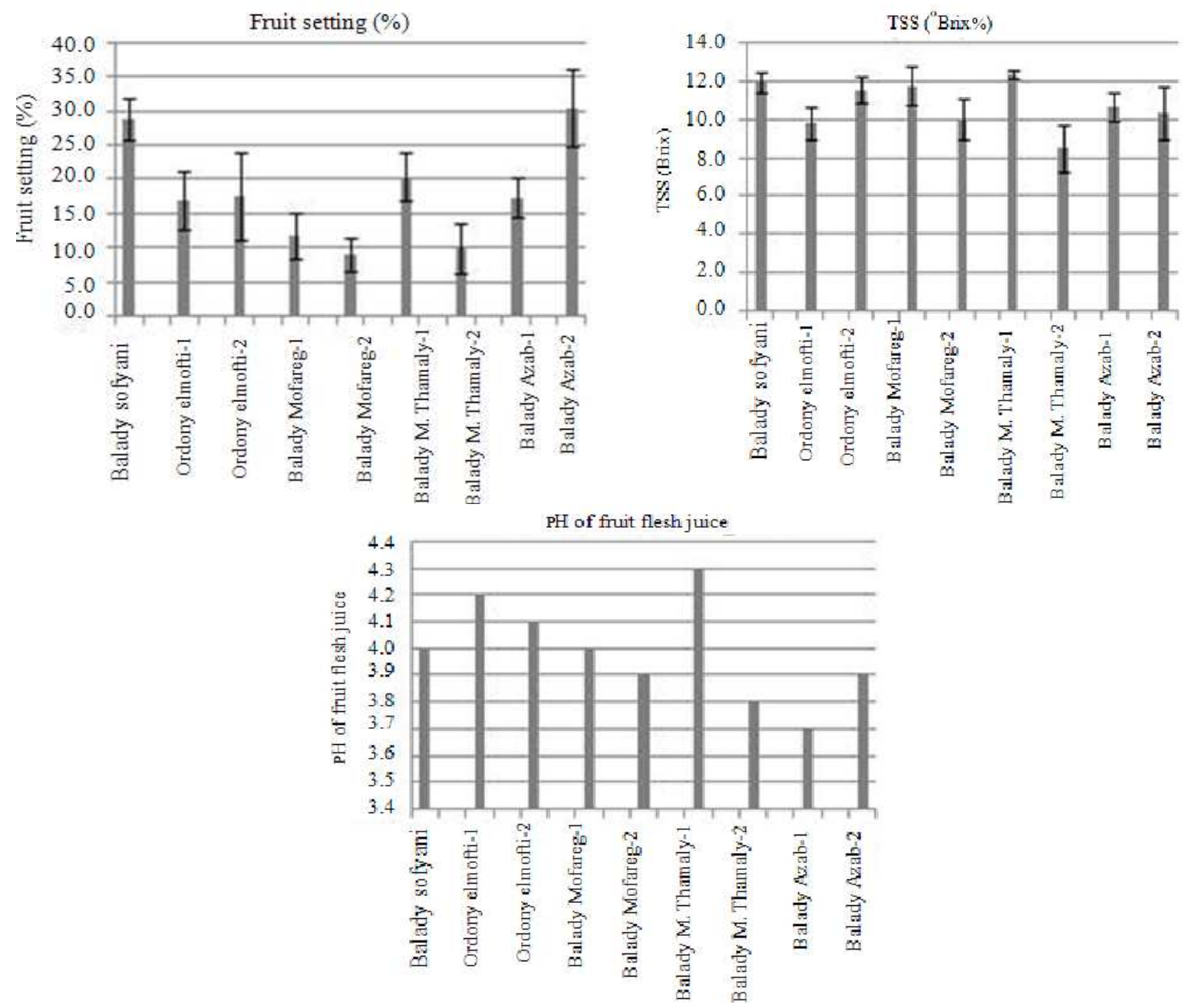

Fig. 1: Quantitative fruit parameters in the studied peach cultivars. The x-axis represents the different cultivars studied. The different $y$-axes represent the different quantitative traits measured

\begin{tabular}{|l|l|l|l|l|l|l|l|l|l|}
\hline \multirow{2}{*}{ Marker } & \multicolumn{1}{|l|}{ Cultivar } \\
\cline { 2 - 12 } & C1 & C2 & C3 & C4 & C5 & C6 & C7 & C8 & C9 \\
\hline B1 & 1 & 1 & 1 & 1 & 1 & 1 & 1 & 1 & 1 \\
\hline B2 & 0 & 0 & 0 & 0 & 0 & 0 & 0 & 0 & 1 \\
\hline B3 & 0 & 0 & 0 & 1 & 1 & 1 & 0 & 0 & 0 \\
\hline B4 & 0 & 1 & 0 & 0 & 0 & 1 & 1 & 1 & 1 \\
\hline B5 & 0 & 1 & 1 & 0 & 0 & 0 & 0 & 0 & 0 \\
\hline B6 & 1 & 1 & 0 & 1 & 1 & 1 & 1 & 1 & 1 \\
\hline
\end{tabular}

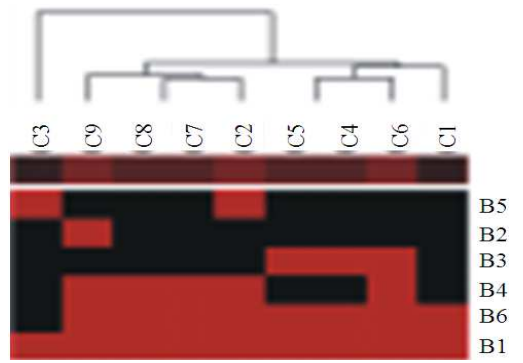

Fig. 2: Qualitative fruit properties in the studied peach cultivars. B1: Fuzz $(1=$ Dense). B2: Cling Stone $(1=$ Freestone, $0=$ Semi-cling). B3: Smell (1: Odor, $0=$ No odor $)$. B4: Taste $(1=$ Sweet, $0=$ Semi-sweet $)$. B5: Fruit Color $(1=$ Dull red, $0=$ Red yellow $)$. B6: Flesh Color $(1=$ Orange Yellow, $0=$ White Yellow $)$. Cultivars: (C1) Balady Sofiani; (C2) Ordony El-mofti 1; (C3) Ordony El-mofti 2; (C4) Balady Mofareg 1; (C5) Balady Mofareg 2; (C6) Balady M. Thamaly 1; (C7) Balady M. Thamaly 2; (C8) Balady Azab 1 and (C9) Balady Azab 2. A graphical display of the cultivars clustered according to the studied fruit properties appears at the right. $\operatorname{Red}=1$. Black $=0$ 

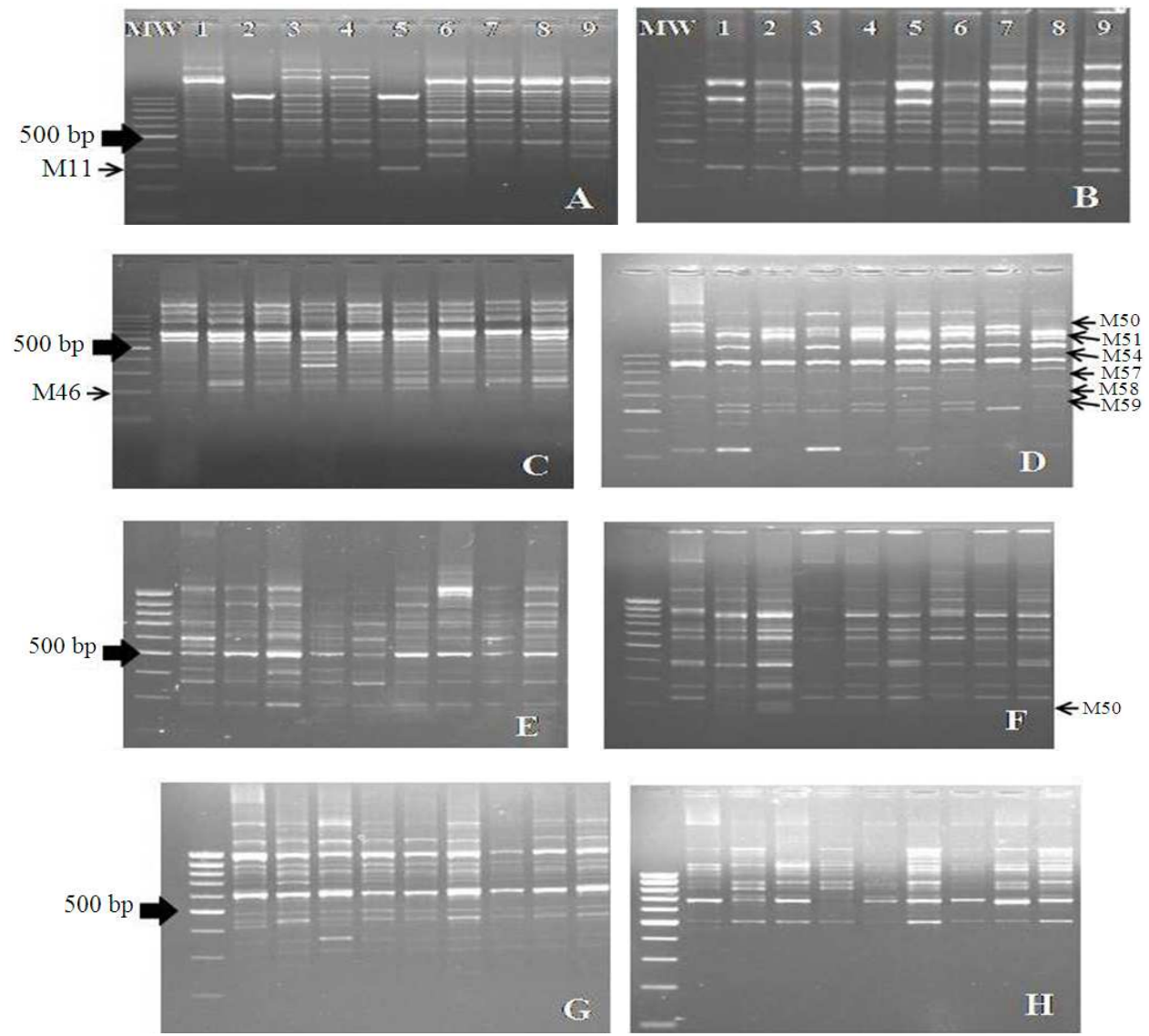

Fig. 3: RAPD fingerprinting of the studied peach cultivars. (A) Primer OP-A08; (B) Primer OP-A13; (C) Primer OP-B07; (D) Primer OP-B10; (E) Primer OP-B18; (F) Primer OP-C20; (G) Primer OP-O04 and (H) Primer OP-Z13. (1) Balady Sofiani; (2) Ordony El-mofti 1; (3) Ordony El-mofti 2; (4) Balady Mofareg 1; (5) Balady Mofareg 2; (6) Balady M. Thamaly 1; (7) Balady M. Thamaly 2; (8) Balady Azab 1 and (9) Balady Azab 2). MW is the molecular weight marker (100 bp Ladder). M's are different molecular markers (RAPD amplicons) specific to different cultivars

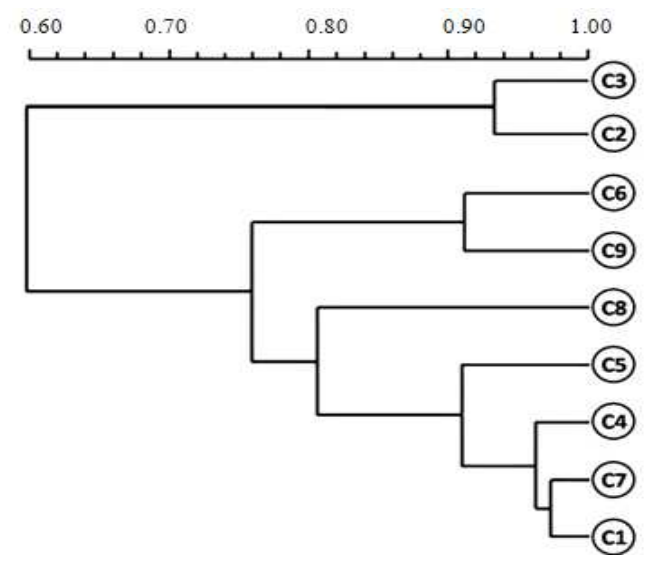

Fig. 4: Cluster analysis of the nine local peach cultivars based on RAPD fingerprinting data: (C1) Balady Sofiani; (C2) Ordony El-mofti 1; (C3) Ordony El-mofti 2; (C4) Balady Mofareg 1; (C5) Balady Mofareg 2; (C6) Balady M. Thamaly 1; (C7) Balady M. Thamaly 2; (C8) Balady Azab 1 and (C9) Balady Azab 2 
Am. J. Applied Sci., 8 (7): 708-715, 2011

Table 2: Monomorphic and polymorphic RAPD amplicons produced from the nine peach cultivars grown in Taif

\begin{tabular}{lclrrr}
\hline Primer ID & Total Amplicons & Size Range (bp) & Monomorphic amplicons & Polymorphic & Polymorphism (\%) \\
\hline OP-A08 & 11 & $300-1700$ & 4 & 7 & 63.6 \\
OP-A13 & 22 & $280-1750$ & 7 & 15 & 68.1 \\
OP-B07 & 13 & $200-1300$ & 10 & 3 & 23.0 \\
OP-B10 & 19 & $330-2000$ & 3 & 16 & 84.2 \\
OP-B18 & 15 & $290-1100$ & 10 & 5 & 33.3 \\
OP-C20 & 12 & $185-1200$ & 2 & 10 & 83.3 \\
OP-O04 & 9 & $300-2000$ & 8 & 1 & 4.1 \\
OP-Z13 & 13 & $500-3000$ & 7 & 63 & 55.1 \\
Totals & 114 & $185-3000$ & 51 & & \\
\hline
\end{tabular}

Table 3: Genetic similarity among the nine peach cultivars calculated from RAPD profiles as Dice coefficients

\begin{tabular}{lrrrrrrrrrr}
\hline & \multicolumn{1}{c}{ C1 } & \multicolumn{1}{c}{ C2 } & \multicolumn{1}{c}{ C3 } & \multicolumn{1}{c}{ C4 } & \multicolumn{1}{c}{ C5 } & \multicolumn{1}{c}{ C6 } & \multicolumn{1}{c}{ C7 } & C8 & C9 \\
\hline C1 & 100.0 & 60.6 & 60.8 & 96.3 & 92.5 & 86.2 & 97.4 & 84.3 & 86.7 & Balady Sofiani \\
C2 & 60.6 & 100.0 & 93.1 & 61.7 & 63.2 & 76.5 & 77.2 & 63.9 & 62.1 & Ordony El-mofti 1 \\
C3 & 60.8 & 93.1 & 100.0 & 61.2 & 62.4 & 76.1 & 77.9 & 64.2 & 63.2 & Ordony El-mofti 2 \\
C4 & 96.3 & 61.7 & 61.2 & 100.0 & 91.7 & 76.8 & 97.3 & 90.1 & 77.1 & Balady Mofareg 1 \\
C5 & 92.5 & 63.2 & 62.4 & 91.7 & 100.0 & 80.9 & 91.4 & 80.8 & 83.2 & Balady Mofareg 2 \\
C6 & 86.2 & 76.5 & 76.1 & 76.8 & 80.9 & 100.0 & 81.2 & 83.2 & 90.6 & Balady M. Thamaly 1 \\
C7 & 97.4 & 77.2 & 77.9 & 97.3 & 91.4 & 81.2 & 100.0 & 84.8 & 77.4 & Balady M. Thamaly 2 \\
C8 & 84.3 & 63.9 & 64.2 & 90.1 & 80.8 & 83.2 & 84.8 & 100.0 & 76.9 & Balady Azab 1 \\
C9 & 86.7 & 62.1 & 63.2 & 77.1 & 83.2 & 90.6 & 77.4 & 76.9 & 100.0 & Balady Azab 2 \\
\hline
\end{tabular}

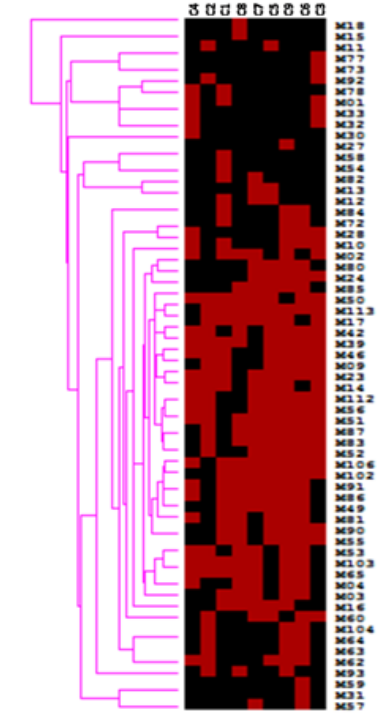

(a)

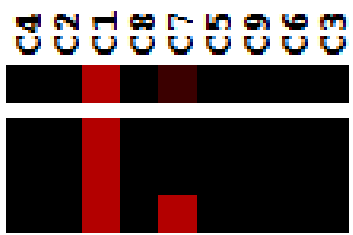

(c)

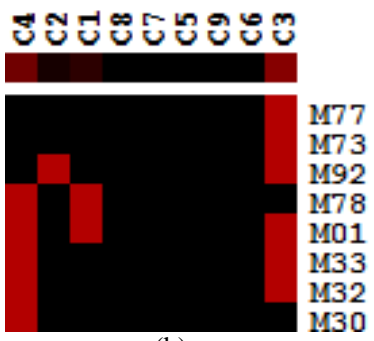

(b)

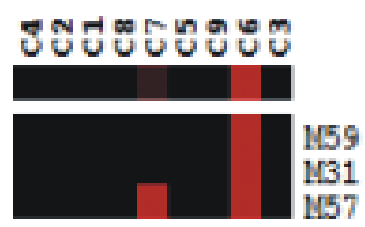

(d)

Fig. 5: (A) Graphical display of the biclustering results. (B) RAPD amplicons M77 and M73 identify cultivar C3. (C) RAPD amplicons M58 and M54 identify cultivar C1. (D) RAPD amplicons M59 and M31 identify cultivar C6. Cultivars: (C1) Balady Sofiani; (C2) Ordony El-mofti 1; (C3) Ordony El-mofti 2; (C4) Balady Mofareg 1; (C5) Balady Mofareg 2; (C6) Balady M. Thamaly 1; (C7) Balady M. Thamaly 2; (C8) Balady Azab 1; and (C9) Balady Azab 2 


\section{DISCUSSION}

The biclustering and display of data in the form of a heatmap (Fig. 5A) allowed for an easy visualization of the results. Figure 5B shows that the cultivar Ordony El-mofti 2 (C3) had the highest fruit length, width ratio and displayed a unique molecular marker combination (i.e., M77 and M73). Figure 5C shows that the cultivar Balady Sofiani (C1) had the highest fruit weight, flesh weight and flesh thickness and displayed a unique molecular marker combination (i.e., M58 and M54). Figure 5D shows that the cultivar Balady M. Thamaly 1 (C6) had the highest TSS\% and a unique combination of biological markers (i.e., B3: odor; and B4: sweet taste) and displayed a unique molecular marker combination (i.e., M59 and M31). Therefore, RAPD fingerprinting confirmed the morphological analyses results and also provided certain molecular markers that might be associated with certain commercial characteristics. In agreement with previous studies reported by Erturk et al. (2009) on the characterization of peach cultivars by using RAPD markers, the results of the present study will allow for future studies on the appropriate use of these cultivars in breeding programs, proper biodiversity assessment and better conservation of germplasm resources.

\section{CONCLUSION}

About 55\% of the RAPD amplicons studied were polymorphic among the studied cultivars. Cluster analysis of RAPD data distinguished all of the studied cultivars. The fingerprinting results agreed with the pomological data. Certain combinations of molecular markers were amplified only from certain cultivars that possessed interesting fruit characteristics (i.e., shape, weight, flesh, taste, and odor). These probable association(s) should be elucidated further in future studies.

\section{ACKNOWLEDGEMENT}

This study has been financed by the project 2008161-429-01 from the Taif University, Ministry of Higher Education, Saudi Arabia. The authors are grateful to the Taif University for financial assistance. We gratefully acknowledge Prof. Said Amin, Biotechnology Department, Taif University for his assistance with statistical analysis program.

\section{REFERENCES}

AOAC, 1990. Official methods of analysis of the Association of Official Analytical Chemists: Food composition, additives, natural contaminants. 16th Edn., The Association, University of Chicago, Washington, DC., ISBN: 0935584420, pp: 614.
Bouhadida M., A. Maria., M. Jose, A. Pere, M. Ngeles and G. Yolanda, 2009. Molecular characterization and genetic diversity of Prunus rootstocks. Sci. Horticul., $\quad 120$ : 237-245. DOI: 10.1016/J.SCIENTA.2008.11.015

Chen, Y., and H. D. Wilde, 2011. Mutation scanning of peach floral genes. BMC Plant Biol., 11: 96. DOI: 10.1186/1471-2229-11-96

Erturk, Y., S. Ercisli, D. Maghradze, E. Orhan and G. Agar, 2009. An assessment of genetic variability and relationships among wild-grown blackthorn plants based on RAPD markers. Genet. Mol. Res., 13: 1238-1244. PMID: 19876864

Falchi, R., G. Cipriani, T. Marrazzo, A. Nonis and G. Vizzotto et al., 2010. Identification and differential expression dynamics of peach small GTPases encoding genes during fruit development and ripening. J. Exp. Bot., 61: 2829-2842. DOI: $10.1093 / \mathrm{j} x \mathrm{~b} / \mathrm{erq} 116$

Jimenez, S., Z. Li, G.L. Reighard, and D.G. Bielenberg, 2010. Identification of genes associated with growth cessation and bud dormancy entrance using a dormancy-incapable tree mutant. BMC Plant Biol., 10: 25. DOI: 10.1186/1471-2229-10-25

Li, X., L. Shangguan, C. Song, C. Wang and Z. Gao et al., 2010. Analysis of expressed sequence tags from Prunus mume flower and fruit and development of simple sequence repeat markers. BMC Genet., 11: 66. DOI: 10.1186/1471-2156-11-66

Nas, M.N., B. Yuksel and B. Adem 2011. Genetic diversity and phylogenetic relationships of Prunus microcarpa C.A. Mey. subsp. tortusa analyzed by Simple Sequence Repeats (SSRs). Sci. Horticul., 127: 220-227. DOI: 10.1016/J.SCIENTA.2010.09.018

Pedryc, A., S. Ruthner and R. Herman, 2009. Genetic diversity of apricot revealed by a set of SSR markers from linkage group G1. Sci. Horticul., 121: 19-26. DOI: 10.1016/J.SCIENTA.2009.01.014

Ribereau, J., Y. Glories, A. Maujean and D. Dubordier, 2006. The Chemistry of Wine Stabilization and Treatments. 2nd Edn., John Wiley and Sons Ltd., New York, ISBN-10: 0471973637, pp: 404.

Rifaat, M., 2011. Biclustering of RAPD fingerprinting data may reveal features pertaining to genome architecture. Proceedings of the 1st International Genomic Conference in Saudi Arabia, Feb. 16-17, CEGMR, King Abdulaziz University, Jeddah, KSA. $\quad$ pp: 33. http://prod.kau.edu.sa/centers/cegmr/conference/H ome.aspx

Verde I., F. Cattonaro, S. Scalabrin, E. Vendramin and A. Policriti et al., 2011. Whole genome resequencing reveals reduced nucleotide variability. Proceedings of the International Plant and Animal Genomes XIX Conference, Jan. 15-19, San Diego, CA., pp: 15-19. http://www.intlpag.org/19/abstracts/W36_PAGXIX_249.html 